\title{
Fear of the unknown: local knowledge and perceptions of the Eurasian lynx Lynx lynx in western Macedonia
}

\author{
Nicolas Lescureux, John D. C. Linnell, Sabit Mustafa, Dime Melovski \\ Aleksandar Stojanov, Gjorge Ivanov, Vasko Avukatov \\ MANUELA VON ARX and URS BREITENMOSER
}

\begin{abstract}
The remnant population of Balkan lynx Lynx lynx martinoi is small, isolated and highly threatened. Since 2006 a conservation project has surveyed its status and promoted its recovery in Albania and Macedonia. Eurasian lynx are often associated with conflicts of an economic or social nature, and their conservation requires a focus on the people sharing the landscape with the species. In this study we adopt methods and conceptual frameworks from anthropology to explore the local knowledge and perceptions of lynx among rural hunters and livestock breeders in the western mountains of the Republic of Macedonia in south-east Europe. The main finding was that local people rarely saw or interacted with lynx. As the level of interactions with this species is very low, the lynx doesn't appear to be a species associated with conflicts in Macedonia. There was also a general lack of both scientific and local knowledge, which has led to somewhat negative attitudes, mainly based on myths and rumours. Poaching of lynx and their prey seem to be the main barriers to lynx conservation.
\end{abstract}

Keywords Balkan lynx, conflict, conservation, ethnoecology, fear, knowledge, Lynx lynx martinoi, perception

This paper contains supplementary material that can be found online at http://journals.cambridge.org

\section{Introduction}

The late 19th to the early 2oth century was the nadir for most large carnivores in Europe (Breitenmoser, 1998; Boitani, 2003). Persecution, prey reduction and habitat conversion drove them to the edge of regional extinction.

Nicolas Lescureux (Corresponding author) and John D.C. Linnell Department of Terrestrial Ecology, Norwegian Institute for Nature Research, NO-7485 Trondheim, Norway. E-mail nicolas.lescureux@gmail.com

Sabit Mustafa, Dime Melovski, Aleksandar Stojanov, Gjorge Ivanov and Vasko Avukatov Macedonian Ecological Society, Skopje, Republic of Macedonia

Manuela von Arx KORA, Muri, Switzerland

URS BREITENMOSER Institute of Veterinary Virology, University of Bern, Bern, Switzerland

Received 25 March 2010. Revision requested 29 June 2010.

Accepted 24 August 2010. First published online 31 August 2011.
Eurasian lynx Lynx lynx were severely affected and only four populations survived into the mid 2oth century (Breitenmoser \& Breitenmoser-Würsten, 2008). Three of these populations (Scandinavian, eastern Baltic and Carpathian) have successfully recovered and other populations have been reintroduced to parts of their former range in central Europe, with varying success (Breitenmoser \& Breitenmoser-Würsten, 2008; Linnell et al., 2009). As a result of these recoveries in Europe and the general status of the species elsewhere in Eurasia, the species is categorized as Least Concern on the IUCN Red List. However, there are some populations that have not recovered, and one of these is the Balkan lynx population, which is recognized as the subspecies Lynx lynx martinoi (Mirić 1974, 1978). This remnant has persisted in the region straddling the AlbanianMacedonia border and a project was initiated in 2006 to promote the recovery of this lynx population (Breitenmoser et al., 2008).

Because Eurasian lynx, like all large carnivores, are often associated with a wide range of economic and social conflicts (Odden et al., 2002; Skogen, 2003; Zimmermann et al., 2010) there is a need to focus on the people who share the landscape with the species as well as on the ecological issues when developing a conservation strategy (Bath, 1996). A diverse range of disciplines have contributed to this (Decker et al., 2001; Manfredo, 2008; Baruch-Mordo et al., 2009). Anthropology has also begun to focus its attention on biodiversity conservation issues, documenting the importance of local knowledge and practices for the conservation of threatened species, and studying perceptions and concerns about biodiversity held by conservationists and local people (Orlove \& Brush, 1996). Local knowledge can provide contextualized data for species conservation (Anadon et al., 2009) and perspectives on conservation and protected areas are avenues of enquiry that can potentially provide sources of information to advance understanding of both human cultures and human-conservation conflicts.

The primary aims of this study were to (1) gather local knowledge and perceptions concerning the lynx, (2) explore potential obstacles, both material and perceptual, to lynx conservation, and (3) develop a set of recommended actions that could be implemented to advance lynx conservation in the region. Secondary aims included exploration of 
the diversity of human-animal relationships within an anthropological framework in a region where they have not been previously studied, and testing theories concerning perception and interaction with a species that is relatively elusive.

\section{Study site}

Western Macedonia is the only area where a reproductive population of Balkan lynx has been confirmed in recent years (Ivanov et al., 2008). The study was conducted in the Polog and Yugozapaden regions of Macedonia during 2007-2008 (Fig. 1), where altitudes are 450-2,000 m. The region is predominantly rural, consisting of towns and agricultural areas in the valleys, with forested slopes, and alpine meadows at higher altitudes. Villages are scattered throughout the landscape but the human population has declined dramatically in recent years. There is little industry and lifestyles are relatively traditional. The region is occupied by both ethnic Albanians and ethnic Macedonians. Wolves Canis lupus and brown bears Ursus arctos are also present. Prey include roe deer Capreolus capreolus, chamois Rupicapra rupicapra, wild boar Sus scrofa and brown hare Lepus europaeous. The forests are used for hunting and forestry, and the alpine meadows are used by both transhumant and resident shepherds with their sheep from May to October.

\section{Methods}

We adopted the methods and conceptual frameworks of ethno-ethological research (Brunois, 2005; Lestel et al., 2005; Lescureux, 2006), which seeks to integrate non-

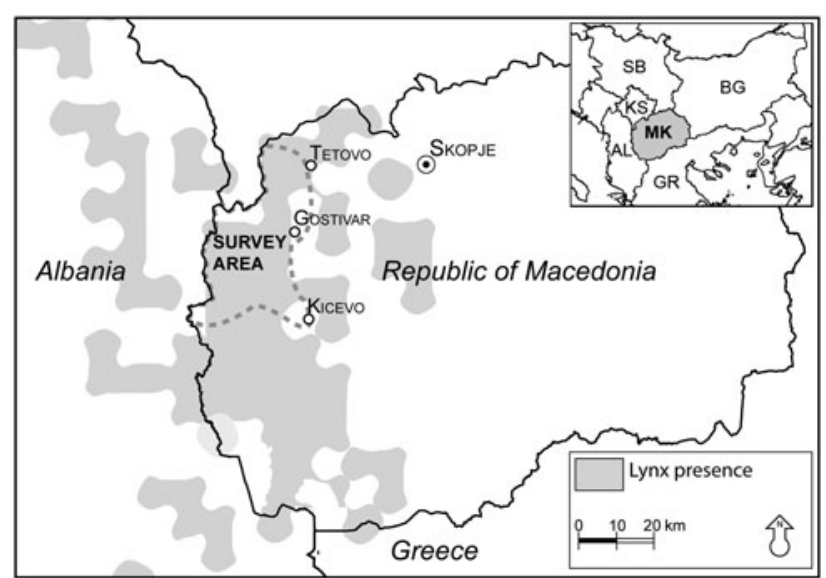

FIG. 1 The potential or probable presence of the Balkan lynx Lynx lynx martinoi (from Breitenmoser \& BreitenmoserWürsten, 2008) and the location of the survey area. The inset shows the location of the Republic of Macedonia (shaded grey) in Europe. human animals into research as interactive social subjects rather than passive objects. Even though anthropological research has shown that local ecological knowledge emerges from interactions with the environment (Barrau, 1975; Descola, 1986; Ellen, 1993) the recognition of the interactive properties of human-animal relationships has taken time to develop as it required rethinking the boundary between nature and culture in general, and the place of animals in anthropology in particular (Descola, 2005). Now, animals have begun to be integrated into anthropological studies as interactive subjects that influence human social life (Ingold, 2000). Their specific behaviours and the way they interact with people are examined to understand how they influence people's perceptions and knowledge. Thus, by focusing on human-animal interactions and local knowledge of animal behaviour and ecology, ethnoethological research seeks to highlight the influence of animal behaviour on society's practices, knowledge and conceptions.

Accordingly, we explored the knowledge and perceptions of lynx among rural people in the western mountains of the Republic of Macedonia. Looking for people who were most relevant for lynx conservation and most likely to have interactive relationships with the species, we focused on livestock breeders and hunters. The search for informants among these focus groups was opportunistic, asking people in the villages where to find hunters or livestock breeders. Because of the low number of livestock breeders and the small populations in most villages we had to visit 33 villages (Table 1). Our objective was not to obtain a representative sample of the Macedonian rural population but to gather enough stakeholders to describe the mechanisms by which their knowledge and perceptions are built in interaction with their social and ecological environment.

Semi-structured in-depth interviews contained 143 questions for livestock breeders and 120 questions for hunters (Appendix). The first section dealt with the activity of the informant and contained questions about hunting or livestock breeding practices. The second was about the nature and frequency of interactions with bears, wolves and lynx. The third focused on aspects of the biology and behaviour (e.g. diet, reproduction, hunting, parental care) of the species. The fourth dealt with perceptions of the species (harmfulness, dangerousness) and opinions about appropriate management practices. The last section contained questions about the definition and perceptions of nature in general and recent changes in the landscape. Interviews were conducted by $\mathrm{NL}$ accompanied by native Albanian or Macedonian speakers, digitally recorded, and later transcribed and translated. Informants were interviewed separately. Interviews typically lasted 1 hour and were conducted in cafes, in private homes or outside. A total of 63 people were interviewed: 34 livestock breeders and 29 hunters (Table 2). 
TABLE 1 List of municipalities and villages investigated in 2007 and 2008 , with the number of inhabitants and total informants, broken down into hunters and livestock breeders.

\begin{tabular}{|c|c|c|c|c|}
\hline $\begin{array}{l}\text { Village or city } \\
\text { (by Municipality) }\end{array}$ & $\begin{array}{l}\text { No. of } \\
\text { inhabitants }^{*}\end{array}$ & $\begin{array}{l}\text { No. of } \\
\text { informants }\end{array}$ & $\begin{array}{l}\text { No. of } \\
\text { hunters }\end{array}$ & $\begin{array}{l}\text { No. of } \\
\text { livestock } \\
\text { breeders }\end{array}$ \\
\hline \multicolumn{5}{|l|}{ Debar } \\
\hline Mogorche & 1,794 & 3 & 1 & 2 \\
\hline Osoj & 6 & 2 & 2 & 0 \\
\hline \multicolumn{5}{|l|}{ Gostivar } \\
\hline Brodec & 7 & 1 & 0 & 1 \\
\hline Gorno Jelovce & 2 & 1 & 0 & 1 \\
\hline Gostivar & 35,847 & 2 & 2 & 0 \\
\hline Kichevo: Kichevo & 27,067 & 2 & 1 & 1 \\
\hline \multicolumn{5}{|c|}{ Mavrovo/Rostushe } \\
\hline Adzievci & 149 & 1 & 1 & 0 \\
\hline Bitushe & 96 & 1 & 0 & 1 \\
\hline Galichnik & 3 & 3 & 1 & 2 \\
\hline Janche & 146 & 1 & 1 & 0 \\
\hline Lazaropole & 2 & 2 & 1 & 1 \\
\hline Leunovo & 6 & 1 & 0 & 1 \\
\hline Mavrovo & 166 & 2 & 1 & 1 \\
\hline Nikiforovo & 10 & 1 & 1 & 0 \\
\hline Rostushe & 872 & 1 & 1 & 0 \\
\hline Vrben & 142 & 1 & 0 & 1 \\
\hline \multicolumn{5}{|l|}{ Tetovo } \\
\hline Bozovce & 924 & 2 & 1 & 1 \\
\hline Lisec & 692 & 1 & 0 & 1 \\
\hline Shipkovica & 2,826 & 4 & 2 & 2 \\
\hline Veshala & 1,222 & 3 & 2 & 1 \\
\hline \multicolumn{5}{|l|}{ Vrapchishte } \\
\hline Dobri Dol & 5,223 & 8 & 2 & 6 \\
\hline Gjurgjevishte & 403 & 2 & 1 & 1 \\
\hline Kalishte & 681 & 1 & 1 & 0 \\
\hline Lomnica & 574 & 5 & 3 & 2 \\
\hline Negotino & 3,673 & 2 & 2 & 0 \\
\hline Pozharane & 26 & 2 & 0 & 2 \\
\hline Senokos & 1,634 & 1 & 1 & 0 \\
\hline Toplica & 1,274 & 3 & 0 & 3 \\
\hline Vrapchishte & 4,874 & 2 & 0 & 2 \\
\hline \multicolumn{5}{|l|}{ Zajas } \\
\hline Leshnica & 219 & 1 & 1 & 0 \\
\hline Tajmishte & 107 & 1 & 0 & 1 \\
\hline
\end{tabular}

${ }^{\star}$ From Macedonian State Statistical Office (2002)

\section{Results}

The results indicate that lynx is a poorly known species in the region. Few of the respondents had seen a lynx more than once in their life and local knowledge of the species' biology was limited. Even though the hunters and livestock breeders were often outside in the high mountain pasture or in the forest, the majority $(56 \%, \mathrm{n}=63$ : note that $\mathrm{n}$ refers to the number of people who answered the specific question, which could change according to the question) had never seen a lynx. Some were even unaware of its existence or identity, despite the fact that lynx are depicted on one of the commonest coins (five Denars) in Macedonia:
'The lynx? What's that? A squirrel or maybe a fox? What did you call it?' Moreover, among people who had encountered this animal $(n=28)$, most $(75 \%)$ had only seen it 1-3 times. There was a difference between hunters and livestock breeders: $55 \%$ of hunters $(n=28)$ had seen a lynx compared with only $35 \%$ of livestock breeders $(n=29)$. There was also a regional difference: $75 \%$ of hunters and $60 \%$ of livestock breeders from Mavrovo municipality $(\mathrm{n}=27)$ had seen a lynx, compared with only 33 and $21 \%$ from Gostivar municipality $(n=26)$ and 60 and $0 \%$ from Tetovo municipality $(\mathrm{n}=10)$.

\section{A poorly known species}

As a consequence of the lack of interactions with the lynx, local knowledge of the species was generally low. Many informants admitted their ignorance about the species, and the majority were unable to answer questions about lynx behaviour and ecology. For those who gave answers, the lynx was perceived as being a solitary and territorial animal, living in rocky and inaccessible places, far from human activities. Contrary to bears or wolves, lynx were not perceived to enter or approach villages. Even though $70 \%$ of informants $(n=63)$ maintained the lynx is a carnivore, $30 \%$ didn't know what its diet consists of. Many informants considered the lynx a 'bloodthirsty' animal. There were many discrepancies between informants concerning the diet of the lynx, notably its propensity to attack domestic animals. This could be partly explained by the fact that they perceived the weight of the lynx to be 15-120 kg (adult lynx weigh 16-22 kg, cf. Breitenmoser \& Breitenmoser-Würsten, 2008). Although some informants, mainly hunters, reported that lynx diet was principally composed of roe deer, hares and birds, some of them considered that the lynx could attack anything: '[The lynx] also attacks domestic animals. (...) Cows, sheep, horses, everything it sees, and everything it encounters'. Even the livestock guarding dogs were sometimes regarded as being unable to protect the flocks as the lynx could also attack dogs: 'I heard shepherds saying that lynx are even more dangerous than wolves and they attack dogs first, and they also kill dogs [...]. [The dogs] are big but he [the lynx] is quite fast and he attacks with his claws towards the eyes'. However, one livestock breeder reported that his dogs had killed a lynx and other informants believed that lynx were afraid of dogs and have no ability to attack domestic animals: '[The lynx] cannot attack big animals. For example, it can attack a lamb... a ewe too, but it waits until it dies and it eats it afterwards, because it cannot overcome it, it is not strong enough, it is as little as a hunting dog'.

Concerning the hunting methods of the lynx, a widespread assertion among informants was that they often attack their prey by jumping from trees or from rocks: 'We do not know exactly how lynx hunt but they climb on 
TABLE 2 Number of informants in each municipality by activity and ethnicity.

\begin{tabular}{|c|c|c|c|c|}
\hline \multirow[b]{2}{*}{ Municipality } & \multirow[b]{2}{*}{ Activity } & \multicolumn{2}{|l|}{ Ethnicity } & \multirow[b]{2}{*}{ Total } \\
\hline & & $\begin{array}{l}\text { Albanian } \\
\text { speaking } \\
\text { Macedonian }\end{array}$ & $\begin{array}{l}\text { Slavic } \\
\text { speaking } \\
\text { Macedonian }\end{array}$ & \\
\hline \multirow[t]{2}{*}{ Debar } & Hunters & 0 & 2 & \multirow[t]{2}{*}{5} \\
\hline & Livestock breeders & 0 & 3 & \\
\hline \multirow[t]{2}{*}{ Gostivar } & Hunters & 0 & 2 & \multirow[t]{2}{*}{4} \\
\hline & Livestock breeders & 0 & 2 & \\
\hline \multirow[t]{2}{*}{ Kichevo } & Hunters & 1 & 0 & \multirow[t]{2}{*}{2} \\
\hline & Livestock breeders & 0 & 1 & \\
\hline \multirow{2}{*}{ Mavrovo/Rostushe } & Hunters & 2 & 5 & \multirow[t]{2}{*}{14} \\
\hline & Livestock breeders & 0 & 7 & \\
\hline \multirow[t]{2}{*}{ Tetovo } & Hunters & 5 & 0 & \multirow[t]{2}{*}{10} \\
\hline & Livestock breeders & 5 & 0 & \\
\hline \multirow[t]{2}{*}{ Vrapchishte } & Hunters & 14 & 2 & \multirow[t]{2}{*}{26} \\
\hline & Livestock breeders & 10 & 0 & \\
\hline \multirow[t]{2}{*}{ Zajas } & Hunters & 0 & 1 & \multirow[t]{2}{*}{2} \\
\hline & Livestock breeders & 0 & 1 & \\
\hline Total & & 37 & 26 & 63 \\
\hline
\end{tabular}

trees or on rocks, they wait for the prey to pass and they jump on its back. That's the way they attack the most'. In general, knowledge was disparate. Several assertions were only shared between a few individuals, with no coherence to the whole. For example, several informants maintained that lynx first suck the blood, before eating the prey, and some informants considered that lynx only eat the heads of hares.

Apart from diet and hunting methods, local knowledge concerning lynx behaviour was weak, notably compared to the extensive knowledge the same informants possessed concerning bears and wolves (Lescureux \& Linnell, 2010). Few people could venture an answer to questions about mating period, birth period, litter size and duration of parental care. These few informants predominantly considered that the lynx give birth to one to two cubs and took care of them for c. 1 year. Hunters encountered lynx more frequently and were also better able to answer questions about lynx behaviour but they generally admitted that the main part of their knowledge about lynx came from books or hunting magazines rather than from experience. We also found more knowledgeable people in the Mavrovo municipality where the interactions between people and lynx were more numerous.

\section{A diversity of views about its nature}

In the absence of either extensive local or academic knowledge, the perceptions of the informants concerning lynx were diverse and often contradictory. Among informants who gave their opinion $(n=48)$, the majority $(52 \%)$ considered that lynx were harmful to livestock, and this proportion increased to $68 \%$ among livestock breeders $(n=22)$, although only two direct cases of attacks were reported by informants. Thus, the harmfulness of the lynx is more speculated upon than proven: '[The lynx] must be harmful since he is living in the forest, so what else can it eat?' and mainly based on rumours: 'They say [the lynx] is harmful, but we never saw it. But they say it is even more harmful than the wolf. Some informants argued that the lynx is faster and more aggressive than other predators such as bears and wolves, and especially tenacious. However, few informants had personally experienced lynx depredation on sheep, probably due to the fact that sheep are well guarded in the region. All livestock breeders we met employed shepherds and had 3-20 livestock guarding dogs, because of the risks from bears, wolves and theft by humans.

Although only $39 \%(n=26)$ of hunters considered the lynx could be harmful to other animals, some of them assumed the lynx can be harmful to game animals, and even that 'in the forest where there are lynx, you cannot find any hares, because it cleans them out'. Thus, some hunters perceived that lynx could pose a threat to the populations of their game species if they become numerous but it was not a main concern for them as there was also a widespread perception that lynx are rare.

\section{An animal potentially dangerous for humans}

Surprisingly, the lynx was considered a dangerous animal to people, even compared to wolves and bears, and even when none of the informants had ever heard of anybody being attacked by lynx; 44\% of informants who gave their opinion $(n=46)$ assumed that the lynx is dangerous for humans and is not a 'trustworthy' animal. Although the only reported interactions were from informants who had the impression of having been followed by the lynx, many viewed the lynx as being dangerous. This fear was partly 
linked to a perception that lynx can attack from trees, and for that reason they were more afraid of lynx than of wolves or bears: 'The lynx? It is even more dangerous than the wolf and the bear, because the lynx, if it wants to hurt you, it climbs up a tree, you do not know, you just pass there... and that's why I put up my hood, because it can fall upon you, directly on the neck. It is dangerous!' Even a man whose father had been attacked by a bear considered lynx as being more dangerous than bears. For some people this fear of the lynx is obviously present when they have to go outside: 'Me, for example, when I go in the mountains where it is said there are lynx, I go there carefully. I always choose a way far from trees so it cannot attack me from above. I always point the rifle to the top. I say it frankly, because it is quite dangerous'.

An animal too rare to be persecuted but still a victim of poaching

Surprisingly, the rather poor image of the lynx did not lead informants to suggest the need for radical management actions for the species, such as elimination, and $46 \%$ $(n=61)$ were in favour of protection whereas only 10 and $2 \%$ suggested an elimination or a reduction of the population, respectively. Twenty-four percent of informants $(n=61)$ maintained there were no lynx in their region and $47 \%$ declared the lynx was rare. Lynx was not a great concern for many informants, in spite of its negative image: '[Lynx] can be bad where they are too many, but here, they are not enough, we do not complain about them'.

Hunters were more favourable to lynx protection (69\%, $\mathrm{n}=29)$ than livestock breeders $(25 \%, \mathrm{n}=32)$. Several hunters considered that it was a good thing to have many species in their region and as the lynx were not numerous, they should be protected to increase the population. Some of them even considered the lynx is useful for the environment: 'Why not [have lynx]? Each animal is welcome in nature; each animal has its own significance. They are cleaners, they clean carrion and they keep the balance'. However, some informants reported they killed lynx or tried to shoot them when they saw them. Some hunters reported that poachers were still hunting lynx despite the species being protected by national law: 'This animal is very rare, and on top of that, there are poachers. Even if lynx hunting is forbidden, there are poachers who hunt them for their skin, to make trophies'.

Poaching seems to be a widespread activity in Macedonia. Several hunters complained about the lack of respect for hunting rules and laws: 'I say frankly to you, that here, hunting rules do not exist, even if there are hunting periods for each species, because this is not respected, even by hunting clubs!' Some of them reported that people were hunting by night with searchlights or car lights. Although no informants reported recent cases of poison being used, some of them admitted it was used in the past, even by the Mavrovo National Park authorities, and recent cases of poisoning are known in other parts of Macedonia (Petkovski et al., 2003). Moreover, snares and traps are still used by poachers to catch wild boar. Even if several informants pretend it was not used any more, one hunter declared he hunted with rifles and snares and another one said he gave his own traps to another hunter a few years ago: 'I gave traps to another guy [...]. We call them "primki"; these are long car-brake cables'. We also observed a case in which a bear was caught in a snare in the study area.

\section{Discussion}

Even if our results are not representative of the Macedonian population, they allow us to understand how the ecology and behaviour of lynx can influence stakeholders' knowledge and perceptions in the socio-environmental context of north-west Macedonia. The lack of interactions between humans and lynx is probably due to the ecology of the lynx. Although lynx are relatively tolerant of human presence and activity (Sunde et al., 1998; Basille et al., 2009) they are rarely seen and their impact on European culture has been relatively weak compared to that of other large felids in other cultures (Bolgiano, 1995; Saunders, 1998). Krickmann (2001), for example, found only one proverb in Eurasia dealing with lynx, compared to hundreds dealing with wolves and bears. Hunting and travelling at night, dragging their kills into cover, spending days in rugged terrain, rarely vocalizing, and ranging over large areas, lynx are rarely seen even in areas where they are abundant. This behaviour implies there are limited possibilities for encounters between lynx and people and therefore few opportunities for local-, or experience-based, knowledge to accumulate.

In our study the lack of interactions has led to a lack of knowledge about the lynx's behaviour and ecology, and this lack of knowledge is recognized by the informants themselves, with the exception of a few knowledgeable hunters. Bath et al. (2008) also found that hunters had slightly higher knowledge scores than other stakeholder groups in Poland but that knowledge levels were generally low for lynx. This knowledge gap permits the emergence and spread of myths and beliefs, such as that of lynx sucking the blood of their prey. This is one of the most widespread lynx myths in Europe, found also in the Carpathians (Breitenmoser \& Breitenmoser-Würsten, 2008) and Scandinavia (JDCL, unpubl. data), and it also concerns large felids such as snow leopards Panthera uncia in Mongolia (McCarthy \& Munkhtsog, 1997) and Kyrgyzstan (NL, unpubl. data). The origins of this myth are not completely disconnected from the behaviour of the lynx, as they probably lie in the fact that lynx normally kill their prey with a throat bite (Krofel et al., 2009), which leads to rapid death from which there is little bleeding (because of little 
tissue damage), giving the mistaken impression that the prey has been emptied of blood. This observation implies a certain familiarity with prey killed by lynx, although it is unclear if the blood sucking interpretation is a local myth that has independently developed or comes from communication with other regions.

Even if the perceptions were not strong, they tended to be slightly negative, in contrast to the extremely negative views that were held about wolves (Lescureux \& Linnell, 2010). There was a general perception that lynx are potentially harmful to livestock (a perception well documented in areas where sheep are grazed without guarding; Stahl et al., 2001; Odden et al., 2002) but at much lower levels than for wolves. The negative image of the lynx is also linked with the fact that they are perceived as dangerous for human safety and could drop from trees onto your back. This myth is widespread in the Balkans (Zoto, 2001) but is also present in historical literature from Germany and the Alps (Breitenmoser \& Breitenmoser-Würsten, 2008), although several decades of field research, using techniques including radio-telemetry and snow-tracking, have not revealed any tendency for lynx to attack from elevated sites (Haglund, 1966) or to attack humans. Despite extensive contemporary and historical documentation of attacks on humans by large carnivores (Löe \& Røskaft, 2004) there are no reports of fatal lynx attacks from Europe. Widespread fear of lynx was also reported in Bath et al.'s (2008) study in Poland but in studies in Norway and Finland (Røskaft et al., 2003, 2007; Liukkonen et al., 2009) it was evident that the fear of lynx was much less than that of wolves or bears. The fear in Macedonia and Poland may result from the low level of interactions that occur, caused by the natural shyness of the lynx, its low density in the region, and the fact that it is not actively pursued as a game species.

Even if local knowledge and perceptions are not directly linked with the behaviour of the lynx, as its behaviour is not known, they are nevertheless a consequence of it. It appears that some of the behaviours of the lynx are partly responsible for the lack of interactions with humans and therefore the development of rumours and beliefs.

The survey provided information of importance for developing a conservation strategy. Although the lynx does not have a positive image, in contrast to the bear, perceptions of the lynx are not as bad as those of the wolf (Lescureux \& Linnell, 2010). Although lynx are perceived as dangerous it is not a matter of concern, as people did not talk about them spontaneously. Most of the negative perceptions were based on an absence of both experience-based and academic knowledge. The virtual absence of interactions with lynx has not prevented the construction of a particular image of the species, and provided the opportunity for rumours to develop and expand without contradiction, apart from among a few knowledgeable hunters. This has led to a disparate kind of knowledge based on a range of beliefs that differ greatly from the consensus view held by ecologists. We thus hypothesize that when the level of interaction is low, the image of the animal is almost completely socially, or even individually, constructed, and determines subsequent practices and emotions associated with it. This image can also be explained by the lack of environmental education in the region, which slows the transfer of knowledge from academic or international sources, and some hunters complained about that.

From telemetry and long-term field studies biologists have accumulated experience- and research-based knowledge of lynx from a wide range of European study areas. This opens the possibility of addressing some of these gaps in local knowledge through information campaigns, although the relationship between knowledge and perception, or attitudes towards wildlife, is complex and contested (Kellert et al., 1996), especially in areas where risk is concerned (Bier, 2001). However, our informants' responses indicated that negative perceptions were neither due to deeply held values, nor to economic or health problems associated with lynx presence. In fact, most wished to protect the lynx and ensure its survival rather than eliminate it. It rather seems that the negative perceptions were due to an absence of experience and knowledge and therefore represented a fear of the unknown. This indicates that an outreach education programme that provides both opportunities for gaining or exchanging experience and information could potentially change perceptions, all the more so as some local hunters indicated a willingness to participate. Developing a cooperative research programme with a high degree of local involvement could also help allow the development of a common knowledge base, as well as building dialogue and trust (Skogen et al., 2008; Liukkonen et al., 2009). The informants, however, especially in the Albanian ethnic community, expressed a deep distrust of most Macedonian institutions. As a consequence much thought would need to go into the design of any education programme, with effort to recruit messengers that have the trust of local people (McComas \& Trumbo, 2001).

The informants also reported that poaching of both lynx and their prey species was widespread. Far from being victims of their image, lynx were reported to be poached both on purpose for their trophy value and accidentally. There was both a widespread lack of knowledge and lack of respect for nature conservation and game management legislation, even in the management institutions, due to more or less institutionalized corruption (Korunovska \& Danilovska, 2005). Many hunters complained about this situation. The widespread existence of poaching has been confirmed by field surveys and other interviews in the region (Ivanov et al., 2008). Poaching seems to be partly by hunters from cities, and local hunters in the villages are complaining about this and could provide support to conservation programmes that aim to prevent poaching. 
There is thus a need for a large-scale outreach programme focused primarily on hunters but also for other rural residents, such as gamekeepers, foresters, livestock breeders and shepherds, to provide information on the full community of wildlife species in the country, including lynx and their key prey species (which, according to many hunters, are also threatened by poaching). This programme should also seek to increase awareness of the conservation problems for individual species. Economic and social conditions are difficult in Macedonia and for many people biodiversity conservation is not a main concern. As one hunter said: 'If we want to go to the police [to complain about poaching], they tell us: "people are being killed, forget about the animals!" It is likely there will need to be radical reform of hunting legislation, and both the willingness and the capacity for implementation, and international experience, suggest that this should be done with extensive participation from key interest groups (Huber et al., 2008). Our study provides a baseline for the design of such a campaign and against which the success of any actions could be measured.

\section{Acknowledgements}

This study was funded by the Norwegian Research Council, the Swiss MAVA foundation and the French Fyssen foundation. During the finalization process, the primary author was also funded by a $\mathrm{FP} 7$ Marie Curie Intra-European Fellowship. We would like to thank Ivana Saltirovska for her help with the translation of interview records.

\section{References}

Anadon, J.D., Giménez, A., Ballestar, R. \& Pérez, I. (2009) Evaluation of local ecological knowledge as a method for collecting extensive data on animal abundance. Conservation Biology, 23, 617-625.

BARRAU, J. (1975) Ecosystèmes, civilisations et sociétés humaines, le point de vue d'un naturaliste. Information en Sciences Sociales, 14, 21-34.

Baruch-Mordo, S., Breck, S.W., Wilson, K.R. \& Broderick, J. (2009) A tool box half full: how social science can help solve human-wildlife conflict. Human Dimension of Wildlife, 14, 219-223.

Basille, M., Herfindal, I., Santin-Janin, H., Linnell, J.D.C., Odden, J., Andersen, R. (2009) What shapes Eurasian lynx distribution in human dominated landscapes: selecting prey or avoiding people? Ecography, 32, 683-691.

B А т , A.J. (1996) Increasing the applicability of human dimensions research to large predators. Journal of Wildlife Research, 1 , 215-220.

Bath, A.J., Olszanska, A. \& Oкавma, H. (2008) From a human dimension perspective, the unknown large carnivore: public attitudes toward Eurasian lynx in Poland. Human Dimension of Wildlife, 13, 31-46.

BIER, V.M. (2001) On the state of the art: risk communication to the public. Reliabililty Engineering and System Safety, 71, 139-150.

Boitani, L. (2003) Wolf conservation and recovery. In Wolves: Behavior, Ecology, and Conservation (eds L.D. Mech \& L. Boitani), pp. 317-344. The University of Chicago Press, Chicago, USA.
Bolgiano, C. (1995) Mountain Lion. An Unnatural History of Pumas and People. Stackpole Books, Mechanicsburg, USA.

Breitenmoser, U. (1998) Large predators in the Alps: the fall and rise of man's competitors. Biological Conservation, 83, 279-289.

Breitenmoser, U. \& Breitenmoser-Würsten, C. (2008) Der Luchs - ein Grossraubtier in der Kulturlandschaft. Salm Verlag, Bern, Switzerland.

Breitenmoser, U., von Arx, M., Bego, F., Ivanov, G., KeÇi, E. \& Melovski, D. (2008) Strategic planning for the conservation of the Balkan lynx. In Proceedings of the III Congress of Ecologists of the Republic of Macedonia with International Participation (o609.10.2007) (ed. Macedonian Ecological Society), pp. 242-248. Macedonian Ecological Society, Struga, Macedonia.

BRUnois, F. (2005) Pour une approche interactive des savoirs locaux: l'ethno-éthologie. Journal de la société des océanistes, 120-121, $31-40$.

Decker, D.J., Brown, T.L. \& Siemer, W.F. (2001) Human Dimensions of Wildlife Management in North America. The Wildlife Society, Bethesda, USA.

Descola, P. (1986) La nature domestiquée. Fondation SingerPolignac, Paris, France.

Descola, P. (2005) Par-delà nature et culture. Gallimard, Paris, France.

Ellen, R. (ed.) (1993) The Cultural Relations of Classification: An Analysis of Nuaulu Animal Categories from Central Seram. Cambridge University Press, New York, USA.

HAGLUND, B. (1966) Winter habits of the lynx (Lynx lynx L.) and wolverine (Gulo gulo L.) as revealed by tracking in the snow [De stora rovdjurens vintervanor I]. Viltrevy, 4, 1-311.

Huber, D., Kusak, J., Majic-Skrbinsek, A., Majnaric, D. \& SinDiCIC, M. (2008) A multidimensional approach to managing the European brown bear in Croatia. Ursus, 19, 22-32.

Ingold, T. (2000) The Perception of the Environment: Essays in Livelihood, Dwelling and Skill. Routledge, London, UK.

Ivanov, G., Stojanov, A., Melovski, D., Avukatov, V., KeÇI, E. \& TrajÇE, A. (2008) Conservation status of the critically endangered balkan lynx in Albania and Macedonia. In Proceedings of the III Congress of Ecologists of the Republic of Macedonia with International Participation (06-09.10.2007). Special Issues of Macedonian Ecological Society, 8, 249-256.

Kellert, S.R., Black, M., Reid Rush, C. \& Bath, A.J. (1996) Human culture and large carnivore conservation in North America. Conservation Biology, 10, 977-990.

Korunovska, N. \& Danilovska, D. (eds) (2005) Macedonia and Corruption-Situation and Challenges. Foundation Open Society Institute, Skopje, Macedonia.

Krickmann (2001) Proverbs on animal identity: typological memoirs. Folklore, 17, 7-73.

Krofel, M., Skrbinsek, T., Kljun, F., Potocnik, H. \& Kos, I. (2009) The killing technique of Eurasian lynx. Belgium Journal of Zoology, 139, 79-80.

Lescureux, N. (2006) Towards the necessity of a new interactive approach integrating ethnology, ecology and ethology in the study of the relationship between Kirghiz stockbreeders and wolves. Social Science Information, 45, 463-478.

Lescureux, N. \& Linnell, J.D.C. (2010) Knowledge and perceptions of Macedonian hunters and herders: the influence of species specific ecology of bears, wolves, and lynx. Human Ecology, 38, 389-399.

Lestel, D., Brunois, F. \& Gaunet, F. (2005) Etho-ethnology and ethno-ethology. Social Science Information, 45, 155-177.

Linnell, J.D.C., Breitenmoser, U., Breitenmoser-Würsten, C., Odden, J. \& von Arx, M. (2009) Recovery of Eurasian lynx in Europe: what part has reintroduction played? In Reintroduction of 
Top-order Predators (eds M. Hayward \& M. Sommers), pp. 72-91. Blackwell Publishing, Oxford, UK.

Liukkonen, T., Mykrä, S., Bisi, J. \& Kurki, S. (2009) Conflicts and compromises in lynx Lynx lynx conservation and management in Finland. Wildife Biology, 15, 165-174.

LÖE, J. \& RøsкAfт, E. (2004) Large carnivores and human safety: a review. Ambio, 33, 283-288.

Macedonian State Statistical Office (2002) 2002 Census. Http:// www.stat.gov.mk [accessed 23 February 2011].

Manfredo, M.J. (2008) Who Cares about Wildlife? Social Science Concepts for Exploring Human-Wildlife Relationships and Other Issues in Conservation. Springer Verlag, New York, USA.

McCarthy, T.M. \& Munkhtsog, B. (1997) Preliminary assessment of snow leopard sign surveys in Mongolia. In Proceedings of the 8th International Snow Leopard Symposium (eds R. Jackson \& A. Ahmad), pp. 57-65. International Snow Leopard Trust and WWF-Pakistan, Islamabad, Pakistan.

McComas, K.A. \& Trumbo, C.W. (2001) Source credibility in environmental health - risk controversies: application of Meyer's credibility index. Risk Analysis, 21, 467-480.

Mirić, D. (1974) Verbreitung des Balkanluchses in der Vergangenheit und heute. Bulletin du museum d'histoire naturelle, Belgrade, Series B, Livre, 29, 51-99.

Mirić, D. (1978) Ausrottungsgeschichte des Luchses auf der Balkanhalbinsel. In Der Luchs-Erhaltung and Wiedereinbürgerung in Europa (ed. U. Wotschikowski), pp. 19-23. Ed. Bernhard, Mammendorf, Germany.

Odden, J., Linnell, J.D.C., Moa, P.F., Herfindal, I., Kvam, T. \& Andersen, R. (2002) Lynx depredation on domestic sheep in Norway. Journal of Wildlife Management, 66, 98-105.

Orlove, B.S. \& Brush, S.B. (1996) Anthropology and the conservation of biodiversity. Annual Review of Anthropology, 25, 329-352.

Petкovski, S., Smith, D., Petroviki, T. \& Sidorovska, V. (2003) Study on Hunting Activities in Macedonia: Past, Present and Future. Society for the Investigation and Conservation of Biodiversity and the Sustainable Development of Natural Ecosystems, Skopje, Macedonia.

Røskaft, E., Bjerke, T., Kaltenborn, B.P. \& Linnell, J.D.C. (2003) Patterns of self reported fear towards large carnivores among the Norwegian public. Evolution and Human Behaviour, 24, 184-198.

Røskaft, E., Handel, B., Bjerke, T. \& Kaltenborn, B.P. (2007) Human attitudes towards large carnivores in Norway. Wildlife Biology, 13, 172-185.

SAUnders, N.J. (1998) Icons of Power: Feline Symbolism in the Americas. Routledge, London, UK.
SKOGEN, K. (2003) Adapting adaptive management to a cultural understanding of land use conflicts. Society and Natural Resources, $16,435-450$.

Skogen, K., MaUz, I. \& KRAnGe, O. (2008) Cry wolf!: narratives of wolf recovery in France and Norway. Rural Sociology, 73, 105-133.

Stahl, P., Vandel, J.M., Herrenschmidt, V. \& Migot, P. (2001) Predation on livestock by an expanding reintroduced lynx population: long term trend and spatial variability. Journal of Applied Ecology, 38, 674-687.

Sunde, P., Sutener, S.Ø. \& Kvam, T. (1998) Tolerance to humans of resting lynxes Lynx lynx in a hunted population. Wildlife Biology, 4, 177-183.

Zimmermann, A., Baker, N., Linnell, J.D.C., Inskip, C., Marchini, S., Odden, J. et al. (2010) Contemporary views on human-carnivore conflicts in Wild Rangelands. In Can Rangelands be Wildlands? Wildlife and Livestock in Semi-arid Ecosystems (eds J. Du Toit, R. Kock \& J. Deutsch), pp. 129-151. Blackwell Publishing, Oxford, UK.

Zото, H. (2001) Rreqebulli. Specie e kërcënuar për zhdukje. Tiranë, Albania.

\section{Appendix}

The appendix for this article is available online at http:// journals.cambridge.org

\section{Bibliographical sketches}

NICOLAS LESCUREUX is an ethno-ecologist who has conducted research on human-large carnivore relationships in France, Kyrgyzstan and Macedonia. His main focus is the way in which carnivore behaviour and ecology can shape human local knowledge and perceptions. JонN LINNELL is an ecologist working on a range of inter-disciplinary approaches to foster wildlife conservation and reduce human-wildlife conflicts. Sabit Mustafa, Dime Melovski, Aleksandar Stojanov, Gjorge Ivanov and Vasko Avukatov are ecologists working with a range of research and conservation projects in Macedonia that try to ensure the country's rich wildlife survives the extreme transitions that the country is undergoing. URS BREIT ENM OSER and Manuela von ARX work with the IUCN Cat Specialist Group, which aims to build the scientific platform needed to achieve conservation of wild felids globally. 